\title{
Orkesterbiblioteket i Det kongelige Bibliotek
}

af overassistent Kurt Ferré Andersen

I Det kongelige Biblioteks Musikafdeling findes Orkesterbiblioteket, som rummer Danmarks største offentlige samling af orkester- og kornoder til opførelsesbrug. Orkesterbiblioteket får årligt henved 1.000 henvendelser fra såvel amatørensembler som professionelle orkestre og kor over hele landet. For at låne kræves blot, at orkestret/koret er fast etableret, at det indregistreres som låner i Orkesterbiblioteket, og at øvrige gældende låneregler overholdes.

Orkesterbiblioteket har nodemateriale til symfoniorkestre, kor, større kammerensembler, harmoniorkestre og salonorkestre, ialt mere end 15.000 værker, nye og gamle, store og små, håndskrevne og trykte, men kun nyere trykte værker kan hjemlånes.

\section{Orkesterkatalog 1-2}

For at imødekomme ønsket fra mange orkesterlånere om en katalog over hvilke værker, der måtte hjemlånes, blev det i 1985 foreslået at gennemgå nodearkiverne med henblik p̊̊ en edb-registrering og fremstilling af en trykt katalog over disse værker. 10 forskningsbiblioteker i Danmark havde på det tidspunkt i nogle år arbejdet med fælles edb-katalogisering SAMKAT, der via et fotosatsprogram kunne producere færdige forlæg til fastformskataloger som f.eks. Dansk Musikfortegnelse. Den 26. marts 1985 sendte Musikafdelingen en ansøgning til bibliotekets edb-udvalg, som godkendte anvendelsen af dette program. I marts 1987 udkom den første katalog over 500 udlånsklare orkester/korværker, alfabetisk ordnet, med uniforme (standardiserede) og bibliografiske titler, værkhenvisninger og med stemmeoptællinger. I januar 1991 færdiggjordes den næste katalog over yderligere 1.000 værker, nu desuden med DK5-klassifikation. Registreringer af nye værker foregår stadig 
og overføres nu løbende til Det kongelige Biblioteks online informationssystem REX.

\section{Oprettelsen og formålet}

Orkesterbiblioteket oprettedes i 1945 på grundlag af en række store samlinger orkester- og kornoder, Det kongelige Bibliotek havde erhvervet. Daværende førstebibliotekar Sven Lunn skrev således i Biblioteksårbogen 1946: "Orkesterbiblioteket har nu fungeret uofficielt i mere end et Aar og har været meget stærkt benyttet af professionelle Orkestre over hele Landet". Om formålet med oprettelsen skriver han, "at samlingen i første Række skal komme det offentlige Musikliv tilgode". 23 år senere stod der i Information om Nordisk Musikforskning II: "Orkesterbiblioteket, stiftet 1945, har udviklet sig til at blive et af de største europæiske i sin art. Det betjener samtlige danske musikinstitutioner og professionelle orkester samt en stor del af amatørorkestrene".

\section{Det kongelige Teaters Nodearkiv}

I 1905 modtog Det kongelige Bibliotek 906 partiturer fra Det kongelige Teater. Den 26. februar 1935 udfærdigedes en overenskomst mellem de 2 institutioner vedrørende en overførsel af partiturer foruden en stor samling orkester- og korstemmer. Det har ikke været med begejstring, at biblioteket modtog samlingen af stemmer, idet der til sidst i overenskomsten kan læses "Foruden de ovenfor nævnte Musikalier ... erklærer Biblioteket sig villigt til at modtage det af det kgl. Teaters store Samling af Opførelsesmateriale (herunder Solo-, Kor- og Orkesterstemmer til Operaer, Syngespil og Balletter), som ikke har øjeblikkelig Interesse for Teatret, men som man dog kan have Interesse af at opbevare under betryggende Forhold". I dag kan vi prise os lykkelige over, at denne enestående samling er bevaret. Der findes operaer, syngespil, vaudeviller, balletter, indlæg og mellemaktsmusik tilbage til Teatrets første egentlige syngespil i 1770 Soliman den Anden med musik af Sarti. Af nationale klenodier kan fra operaens verden nævnes Hornemanns Aladdin, Heises Drot og Marsk, Lange-Müllers Der var Engang, Kuhlaus Elverhøj, Hartmanns Liden Kirsten, Carl Nielsens Maskerade, og fra ballettens Paullis Kermessen i Brügge, Bournonvilles Napoli, Løvenskjold og Bournonvilles Sylphiden. I 1983 overførtes yderligere kor- og orkesterstemmer til 100 operaer og 59 balletter fra den nyere del af Teatrets reper- 
toire, f.eks. Schillers Maria Stuart med musik af Arne Hammelboe og H.C. Andersens Historien om en Moder med musik af Thomas Koppel.

\section{Casino, Røde Kro, Dagmar og Folketeatrets Arkiver}

I 1942 modtog biblioteket Casino Teatrets nodearkiv, som med dets 409 værker og ialt 8.865 stemmebind rummer et væld af kendte teaterstykker og operetter. Vi kan her finde f.eks. Boccaccio, Farinelli, Karlighed uden Strømper og Orfeus $i$ Underverdenen. Fra Dagmar Teatret kom året efter 437 værker med partiturer og 7.418 stemmer. Her fandtes bl.a. Griegs originalmanuskript til opførelsen af Peer Gynt i 1885, originalværker af Hornemann og Carl Nielsen, foruden de udenlandske værker som Mozarts Teaterdirektфren og Offenbachs Theaterbanditterne (!). Fra det populære Røde Kro Teater, der lå på Amager, modtog biblioteket i 1965388 værker med herlige titler som Abekatten, Broder Sjus, De forstyrrede Stavnem $\phi$ der, Fandens Overmand, Fruentimmerhaderen, Penge regerer Verden, Sagt op, foruden de kendte som Eventyr på Fodrejsen, Elverhøj, Frøken Nitouche og

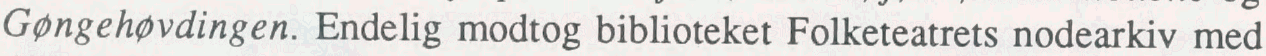
429 værker, af hvilke kan nævnes de store operetter: Farinelli, Orfeus $i$ Underverdenen, Den skønne Helene og Flagermusen.

\section{Cæciliaforeningens Arkiv}

I begyndelsen af det 19. århundrede vågnede interessen for renæssancens og barokkes kirkemusik. Rundt omkring i Europa førte det til dannelse af Cæciliaforeninger, opkaldt efter kirkemusikken skytshelgen, den hellige Cæcilia. Disse foreninger havde til opgave at fremføre navnlig den gregorianske sang og 1500 tallets Palestrinastil.

Den 29. oktober 1851 stiftede Henrik Rung en sådan forening i Danmark. Efter nogle vanskelige år konstitueredes foreningen endeligt i februar 1857 under navnet Cæciliaforeningen. Der indførtes abonnementskoncerter og ret hurtigt derefter blev Cæciliaforeningen en hovedfaktor i det danske koncertliv. Foreningen videreførtes efter Henrik Rungs død i 1871 af sønnen Frederik Rung. Denne efterfulgtes af søstersønnen P.S. Rung-Keller, som i 1931 afløstes af Mogens Wöldike. I Cæciliaforeningens arkiv findes bl.a. kirkelige korværter af Bach, Händel, Haydn og Mozart foruden operaer og udtog af Gluck, Mozart og Rameau. Foreningen opløstes i 1934. Foranlediget af P.S. Rung-Keller modtog biblioteket i februar 1945 Cæciliaforeningens store arkiv 
Henrik Rung (1807-1871). Henrik Rung stiftede Cæciliaforeningen i 1851 og var fra starten dens dirigent. Han var endvidere syngemester ved Det kgl. Teater og komponerede musik til skuespil og til salmer, romancer og sange. Kendte er bl.a. Hr. Peder kasted runer over spange, Kimer, I klokker og I Danmark er jeg født.

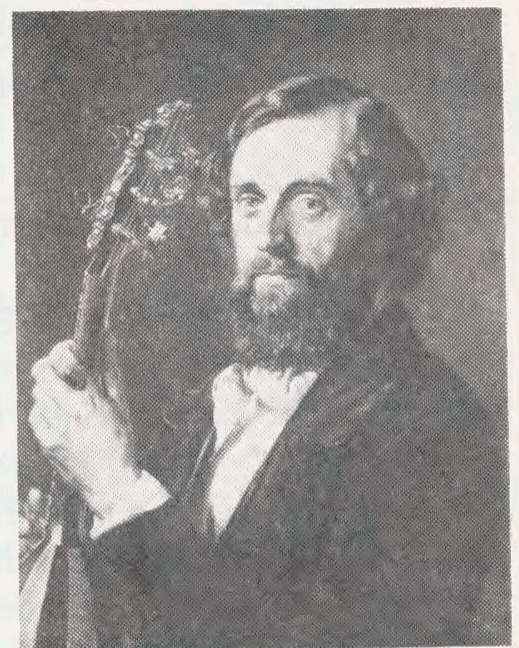

med opførelsesmaterialer til 469 værker med partiturer og 29.998 stemmer på den betingelse, at arkivet skulle komme det offentlige musikliv til gode.

\section{Musikforeningens og Koncertforeningens Arkiver}

Musikforeningen stiftedes den 16. marts 1836 ud fra et $\emptyset$ nske om at udgive danske musikværker og arrangere private koncerter. Franz Gläser blev dirigent for orkestret, som i det store hele bestod af musikere fra Det kgl. Teater. Koncerterne gik godt indtil 1849, hvor Det kgl. Teater overgik til statsdrift og musikernes virksomhed uden for teatret begrænsedes. Man engagerede derefter H.C. Lumbyes Tivoliorkester, og med Niels W. Gade som ny dirigent voksede foreningens koncertliv med talrige koncerter, først i Hofteatret, senere i Casinos store og lille sal. Hyppigt opført var værker af Beethoven, Mendelssohn, Mozart, Gade, Schumann og Schubert. I foreningens storhedsperiode i 1880erne afholdtes ud over 12 faste koncerter årligt også Tivolikoncerter, Folkekoncerter og Palækoncerter i Odd Fellow Palæet. Da Koncertforeningen (se nedenfor) opløstes i 1893, styrkedes Musikforeningen yderligere med tilgang af nye medlemmer, og da Gade afløstes af Emil Hartmann i 1891 og Franz Neruda i 1893, blev foreningen førende i det københavnske musikliv omkring århundredskiftet. Efter dannelsen af Statsradiofoniens Orkester i 1925 og flere andre københavnske musikforeninger blev konkurrencen igen større.

Koncertforeningen i København oprettedes i 1874 og baserede sit repertoire på større korværker og ny musik af bl.a. Schumann og Saint-Saens. Som dirigent fungerede først Otto Malling, senere fulgtes C.F.E. Horneman 


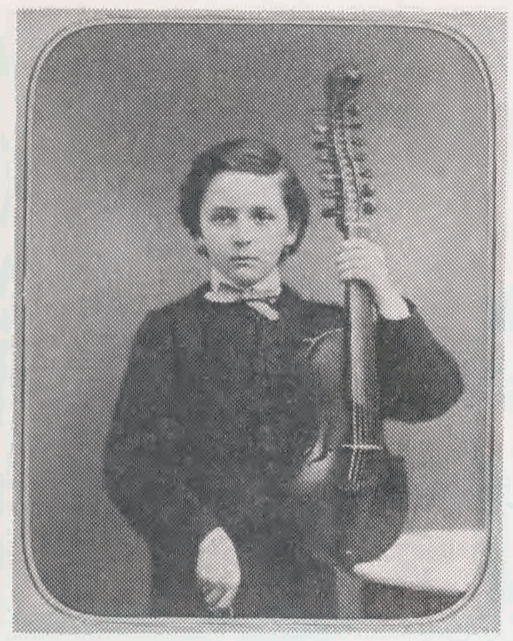

Frederik Rung (1854-1914). Søn af Henrik Rung og dennes efterfølger i Cæciliaforeningen. Har skrevet bl.a. operaer (Det hemmelige Selskab, Den trekantede Hat), balletmusik og store vokalværker.

og Lange-Müller. Foreningen anvendte i flere år sangere fra Det kongelige Teater, men da der i 1892 udstedtes forbud mod anvendelse af disse, samtidig med at der opstod økonomiske problemer, og ikke mindst at medlemstallet svigtede, opløstes Koncertforeningen i 1893. Hele foreningens nodearkiv, som havde kostet $12.000 \mathrm{kr}$. blev solgt til Det kongelige Bibliotek for $1.000 \mathrm{kr}$., hvilket omtrent udgjorde Koncertforeningens gæld. Arkivet bestod, som det siges i likvidationskommissionens skrivelse af "... Blomsten af den udenlandske Musik fra de seneste Aartier..." og videre "... de mest fremragende nordiske Komponister, alle med Arbejder fra den nye og nyeste Tid". Der var partiturer, klaverudtog, orkester- og korstemmer til 150 udenlandske værker for kor og orkester, desuden 50 værker for kor a capella, 50 danske værker for orkester og 150 klaverpartiturer.

Overbibliotekar H.O. Lange skrev imidlertid i 1917 til Musikforeningens formand, professor Angul Hammerich, og tilbød ham at købe kor- og orkesterstemmerne: "Da det mere og mere er blevet tydeligt, at dette store Arkiv af Kor- og Orchesterstemmer ikke hører hjemme i et Bibliotek, idet dets Benyttelse maa være helt andre Regler undergivne, og da det fylder ikke mindre end 18 Meter løbende Hylde, har jeg ment at burde afhænde denne i sig selv meget værdifulde Samling, saa den kan blive opbevaret i en Institutions Værge, hvor den kommer sammen med beslægtede Sager, og hvor den vil kunne gjøre større Nytte i vort Musikliv". Partiturerne og klaverpartiturerne forblev på biblioteket.

I 1935 opløstes Musikforeningen (3/4 år inden den kunne fejre 100 års jubilæum). 345 partiturer købtes af Det kongelige Bibliotek i 1937 for 500 kr., mens stemmematerialet blev overdraget Det kongelige danske Musikkonservatorium. Der forsatte man Musikforeningens mangeårige tradition med at 


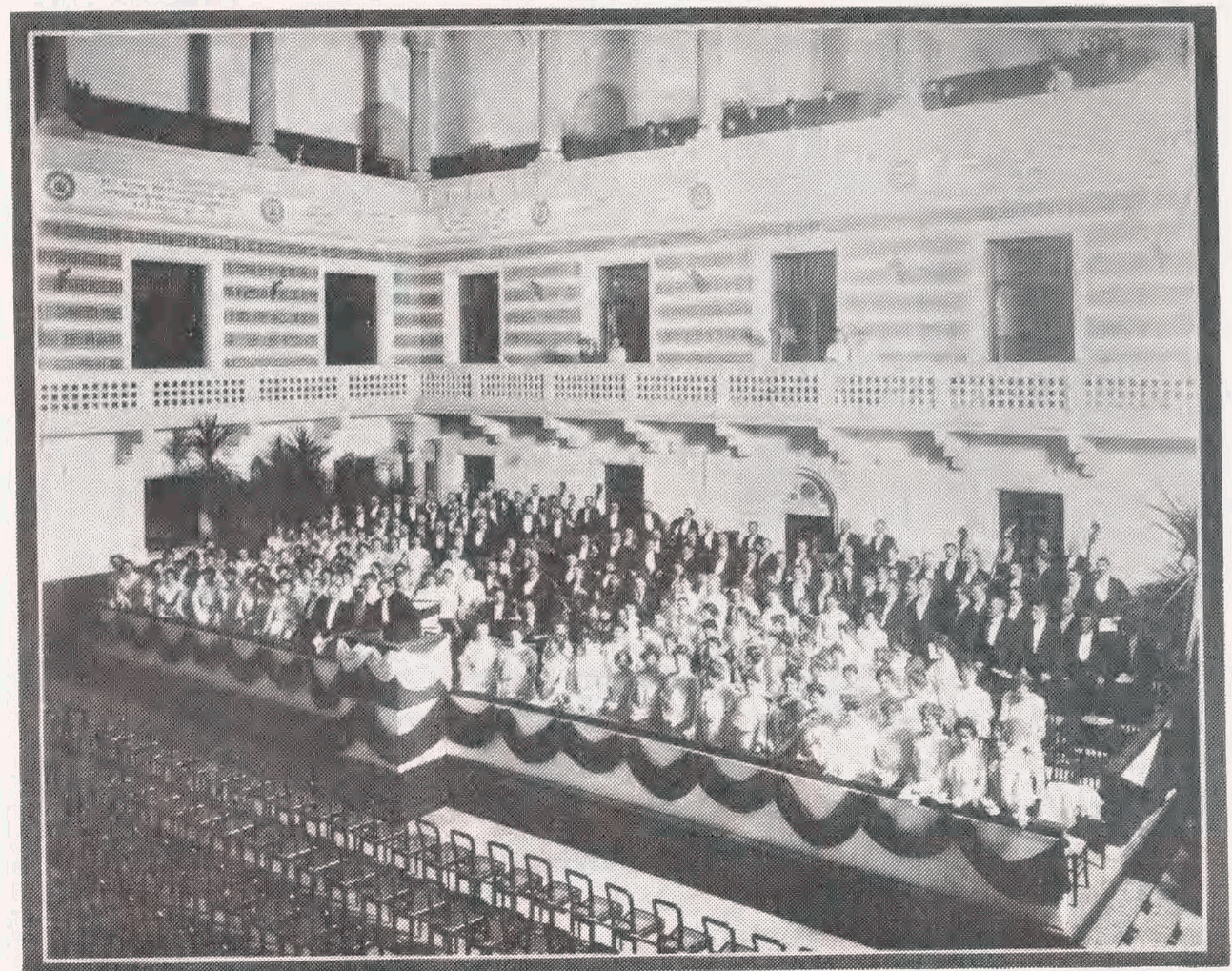

Cæciliaforeningens kor ca. 1905.

udlåne noder til andre orkestre, men da udlånet efterhånden tog for stort et omfang, blev Det kongelige Bibliotek anmodet om at overtage stemmerne og videreføre udlånstraditionen. I april 1945 overførtes ialt 71.814 stemmer til 1337 værker.

\section{Egne afskrifter}

Så godt som al dansk orkestermusik var på den tid håndskrevet, og for at undgå brugen af kostbare originalmanuskripter iværksatte biblioteket i 1943 en storstilet afskrivning af originalpartiturer af danske orkesterværker. Arbejdsministeriet bevilgede $100.000 \mathrm{kr}$. som nødhjælpsforanstaltning til aflønning af arbejdsløse musikere. Der indrettes et særligt nodeskriverrum, hvor afskrivningen fandt sted under førstebibliotekar Sven Lunns ledelse, og der førtes et nøje regnskab med timer og udleverede ark nodepapir. Fra Tivoli erhvervedes ca. 100 originale H.C. Lumbye partiturer mod at biblioteket lod udføre afskrifter (en del af disse afskrifter brændte iøvrigt ved Koncertsalens 
brand i sommeren 1944). Der fremstilledes partiturer og stemmer til bl.a. kantater og korværker af Scheibe, Schultz, Kunzen, Weyse og Hornemann, symfonier af Weyse, Schall, Kunzen, Frøhlich og Hartmann, og ouverturer af Scheibe, Dupuy, Kuhlau, Hornemann, Hartmann og Heise. Bevillingen blev flere gange forlænget, således at afskrivningen kunne fortsætte helt frem til 1958. Mere end 300 værker blev afskrevet i disse år.

\section{Nyere accession}

Efter oprettelsen af Orkesterbiblioteket i 1945 begyndte man at indkøbe, indbinde og udlåne trykte orkesterværker fra engelske og franske forlag. Senere fulgte tyske, italienske og amerikanske forlag. I tidens løb er på den måde opbygget en anselig samling af udenlandske trykte værker, f.eks. de fleste af Bachs kantater, Beethovens symfonier, Händels concerti grossi, Haydns symfonier, serenader og koncerter samt Vivaldis koncerter. I dag findes godt 4.000 værker i biblioteket.

\section{Nyerhvervede arkiver}

Orkesterbiblioteket modtager stadig hele nodearkiver fra ophørte musikforeninger. I 1972 skænkede direktør Erik Krøll biblioteket en samling bestående af ca. 400 værker for harmoniorkester fra Københavns Harmoniorkester, hvor han var dirigent.

I 1988 overførtes fra Musikkonservatoriet en samling på 7-800 værker, som havde tilhørt Dansk Musikerforbund. Heri findes værker for symfoniorkester, harmoniorkester samt nok så spændende: salonorkester. I mange af disse værker ses ejerstempler og optegnelser, der viser, at de bl.a. har været spillet i datidens populære danserestauranter i København: Wivex, Skandia, Nimb og Ambassadeur.

\section{Benyttelsen af arkiverne}

Bibliotekets indstilling til brugen af musikalier er i dag meget liberal, men i bibliotekets årsberetning 1909-18 kan læses "Musikalier udlaanes jo kun til Studiebrug og ikke til Benyttelse for Tidsfordriv". Man skulle studere noderne - ikke spille dem! Da biblioteket modtog Cæcilieforeningens og Musikforeningens arkiver i 1945 var det hensigten, at de fortsat skulle være til gavn 


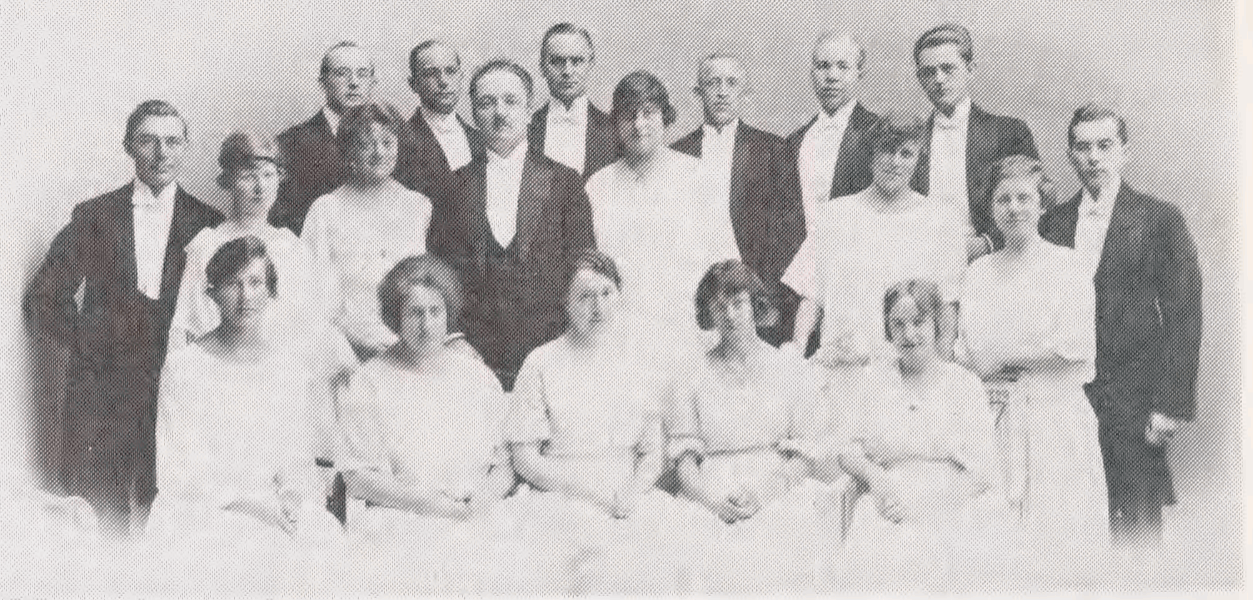

Cæciliaforeningens Madrigalkor 1917.

for det offentlige musikliv. Imidlertid fik kun professionelle orkestre adgang til at låne, og lånetiden var meget kort. I Biblioteksårbogen 1946 skriver Svenn Lunn således: "Om man kan komme så langt, at ogsaa Amatørorkesre vil kunne være laaneberettigede, er ikke alene et Pengespørgsmaal, men afhænger ogsaa af, om de ønskede Musikværker overhovedet kan skaffes". Senere står der vedrørende lånetiden: "Hvor intet andet er aftalt, sættes Laanetiden for Instrumentalmusik til en Maaned og for Værker med Kor til to Maaneder".

Efterhånden som samlingen af nyere trykte værker voksede, udvidedes lånerkredsen til også at omfatte fast etablerede amatøremsembler, musikkonservatorier og -skoler, og lånetiden udvidedes til 3 1/2 måned uanset værkets art. Samtidig begrænsedes udlånet i samlingerne til kun at omfatte trykte værker. Ældre og håndskrevne materialer kan nu kun studeres på Læsesalen. I et vist omfang vil fotokopier kunne tilbydes, idet man dog må betænke, at blot ét værk med partitur og stemmer kan fylde tusindvis af kopisider.

\section{Orkesterbiblioteket i dag}

Orkesterbiblioteket tæller i dag mere end 15.000 værker med over 500.000 stemmer. Den løbende accession på godt 4.000 numre er opstillet i magasinerne i numerus currens, hvorimod teater- og orkesterarkiverne er opstillet $i$ den orden, hvori de er modtaget. Det skyldes, at disse arkiver oftest blev afleveret sammen med en katalog eller fortegnelse over værkerne. I Informationssalen findes en samlet kortkatalog over Musikforeningens arkiv (med opstillingssignatur Mf.), Cæciliaforeningens arkiv (Cf.) Egne Afskrifter (EA) 
og den nye accession (Mf. A). Her findes også en fortegnelse over værker for harmoniorkester. Værker til udlån findes dels i REX (base 11), dels i de trykte kataloger Orkesterkatalog 1-2. Registranter over teaterarkiverne og Dansk Musiker Forbunds arkiv findes kun i Musikafdelingen.

Orkesterbiblioteket er i dag en specialsamling med egne låneregler, egne lånere og egne kataloger. Den fungerer både som national overcentral for opførelsesklare orkester- og korværker, og som enestående studiesamling for ældre orkestermusik og dramatisk musik i Danmark.

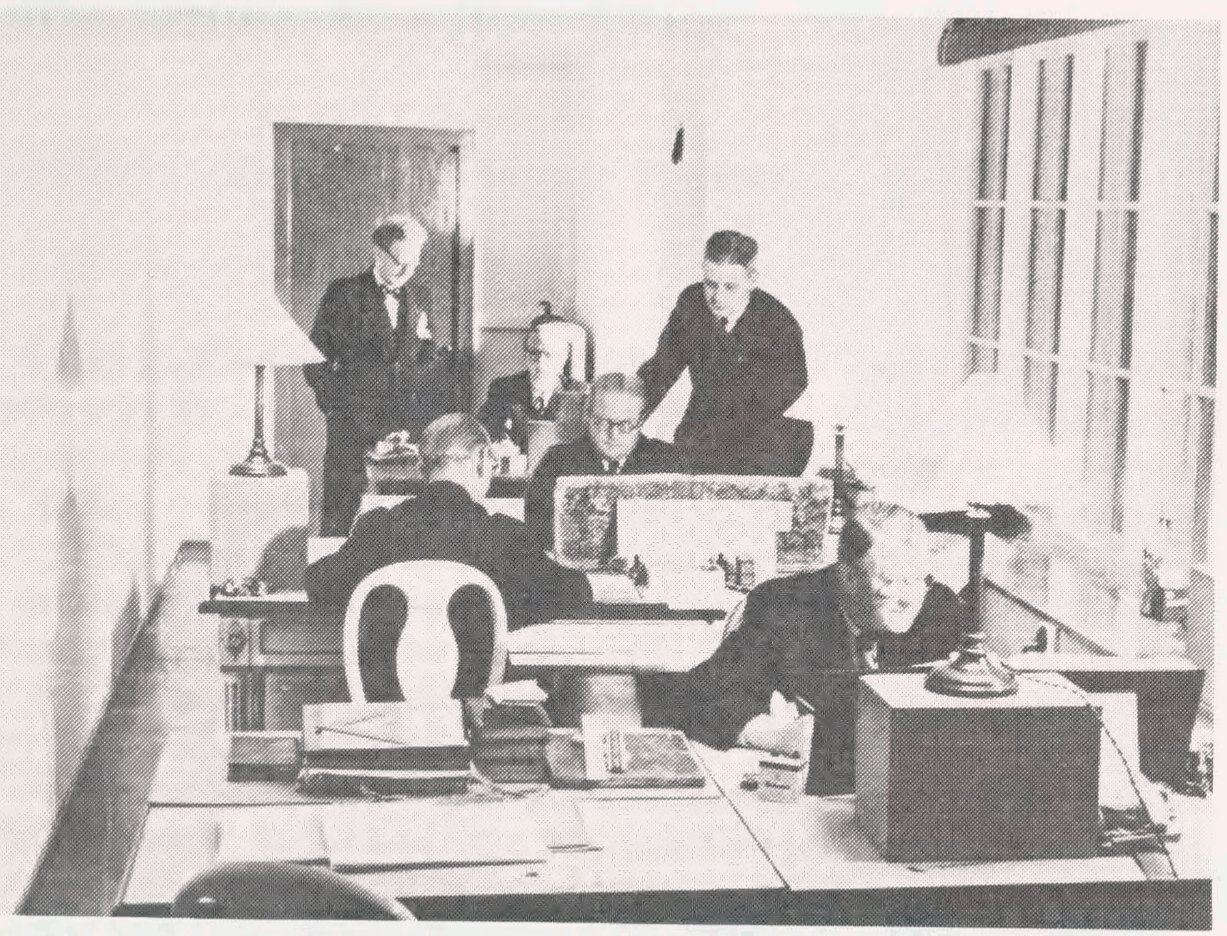

Nodeskriverrummet, som indrettedes i køje D17. Stående ved midterste bord ses førstebibliotekar, mag.art. Sven Lunn (1903-1969). Kort- og Billedafdelingen. 1943.

Kilder

AARSBERETNINGER og Meddelelser fra Det store kongelige Bibliotek 1869-1947. BIBLIOTEKSÅRBOGEN 1946. Udg. af Danmarks Biblioteksforening.

BOGENS VERDEN 1966. Udg. af Danmarks Biblioteksforening.

INFORMATION OM NORDISK MUSIKFORSKNING II. Kbh. 1969. Udg. af Dansk Selskab for Musikforskning.

DANSK AARBOG FOR MUSIKFORSKNING VI. Særtryk. s.a. Udg. af Dansk Selskab for Musikforskning. MUSIKAFDELINGENS arkiv. 
